\title{
Algumas reflexões acerca da geografia socioambiental e comunidade
}

\author{
Marcelo Bêz* \\ Lauro César Figueiredo ${ }^{* *}$
}

\section{Resumo}

Buscando realizar algumas reflexões acerca dos pressupostos da Geografia Socioambiental e do conceito de comunidade, interrelacionadas pelo pensamento complexo, realizou-se uma investigação bibliográfica acerca de alguns autores que pensam o mundo em sua multidimensionalidade. Inicialmente traz-se a perspectiva da Geografia Socioambiental enquanto corrente do pensamento geográfico que apresenta a relação homem e natureza de forma complexa e interconectada. Após, dialogando com a perspectiva socioambiental aborda-se a comunidade enquanto busca por segurança no mundo atual, em seus conflitos e avanços. Assim, desenvolveu-se este estudo como forma de possibilitar aos leitores um refletir sobre as coisas no/do mundo a partir da sua relação com o outro, enquanto um legítimo. Neste mundo onde todos os seres são interdependentes, há tarefas enfrentadas por cada indivíduo, mas com as quais não se pode lidar individualmente.

Palavras-Chave: Geografia socioambiental; Comunidade; Pensamento complexo; Interrelações.

* Graduado em Geografia (Bacharelado e Licenciatura) e Mestrando em Geografia pela UFSM/RS (marcelofresh@hotmail.com).

** Professor do Programa de Pós-Graduação em Geografia e Geociências da UFSMRS (laurocfigueiredo@hotmail.com).

Geosul, Florianópolis, v. 26, n. 52, p 57-76, jul./dez. 2011 
BÊZ, M. \& FIGUEIREDO, L.C. Algumas reflexões acerca da Geografia ...

Reflections about community and social-environmental geography

\section{Abstract}

Starting from the objective of doing some reflections about principles of Social-Environmental Geography and the concept of community, and inter-related by the complex thinking, there has been a bibliographical research about some authors who think the world in its multi-dimensionality. It is initially brought the perspective of the Social-Environmental Geography as a geographic line of thoughts which presents the relationship between man and nature in a complex, inter-connected way. Then, dialoguing with the social-environmental perspective, there's an approach to community as a quest for security at the current world, in its conflicts and advances. So, this study was developed as a way to make possible for readers to reflect about the things in/of the world, from their relation with the other, while a legitimate. In this world where all beings are inter-dependent, there are tasks faced by each and every individual, but with which we cannot deal individually.

Key words: Social-environmental geography; Community; Complex thinking; Inter-relations.

\section{Introdução}

$\mathrm{O}$ artigo em questão tem como objetivo discutir os conceitos de Geografia Socioambiental e comunidade, apresentando seus principais avanços na área. $\mathrm{O}$ debate tem crescido, e alguns autores têm avançado no sentido de buscar um maior entendimento sobre esses conceitos. Nesse sentido, uma visita à literatura produzida nos últimos anos mostra-se como um importante ponto de partida.

Em um primeiro momento realiza-se a abordagem dos pressupostos da Geografia Socioambiental, cujas reflexões ora são enfatizadas enquanto corrente do pensamento geográfico, ora como forma de se pensar e ver as coisas no/do mundo, numa perspectiva 
BÊZ, M. \& FIGUEIREDO, L.C. Algumas reflexões acerca da Geografia ... que possibilita refletir e agir, interrelacionando sociedade e natureza, Geografia Física e Humana, homem e meio, dentre outras dicotomias.

Num segundo momento procura-se adentrar nas idéias que compõem o conceito de comunidade, trazendo pensadores que abordam esta lógica segundo os aspectos socioambientais que a estruturam. Pensando a comunidade enquanto locus de formação e construção dos sujeitos no que se refere a questões como liberdade e segurança, ao mesmo tempo relacionais e excludentes, estruturação de saberes, relacionamentos interpessoais, conflitos, dentre outros processos subjetivos e ao mesmo tempo concretos.

Busca-se explicar a Geografia Socioambiental a partir do conceito de comunidade, bem como o conceito de comunidade na perspectiva da Geografia Socioambiental, por isso as reflexões devem necessariamente estar interligadas ao espaço de análise. Esta forma de pensar e perceber não só a Geografia, mas a própria vida, tentando ir além daquilo que salta aos olhos, no sentido de investigar não só os objetos, mas as suas relações e trocas, fez com que se procurasse trabalhar este nó da imensa rede geográfica: a Geografia Socioambiental.

\section{Pensando a Geografia Socioambiental}

O envolvimento da sociedade e da natureza nos estudos emanados de problemáticas ambientais - nos quais o natural e o social são concebidos como elementos de um único processo resultou na construção de uma nova corrente do pensamento geográfico, aqui denominada Geografia Socioambiental. Segundo Mendonça (2001, p. 122), "Nesta corrente a problemática ambiental na geografia deixa de ser identificada apenas como ligada à geografia física e passa a ser geográfica.".

Este trabalho se inscreve no contexto das problemáticas socioambientais, que nas décadas recentes têm suscitado preocupações e crescente interesse social, além de testemunhar a problematização da relação sociedade e natureza. A questão 
BÊZ, M. \& FIGUEIREDO, L.C. Algumas reflexões acerca da Geografia ...

socioambiental acaba por definir o conjunto das contradições resultantes das interações internas dos sistemas sociais e destes com relação aos sistemas naturais.

A própria natureza da crise socioambiental tem propiciado reflexões e práticas na escala da comunidade orientadas para novas sínteses que articulam cultura e natureza, ciências naturais e sociais, economia e ecologia, ética e política, ciência e religião, entre outras dicotomias até então existentes. O trabalho com os problemas socioambientais através da interrelação homemnatureza, homem-meio e homem-homem busca mobilizar pesquisadores, atores sociais e poder público para refletir e buscar soluções para as questões pertinentes às inquietações da maioria da população.

Nesta pesquisa visa-se trabalhar a Geografia Socioambiental na sua interrelação com a comunidade, abordando para tal o meio natural e social de forma indissociável, em uma perspectiva conexa. Esta abordagem diferenciada da Geografia pode ser mais bem explicada por Mendonça, ao afirmar que:

O envolvimento da sociedade e da natureza nos estudos emanados de problemáticas ambientais, nos quais o natural e o social são concebidos como elementos de um mesmo processo, resultou na construção de uma nova corrente do pensamento geográfico aqui denominada geografia socioambiental (2001, p. 113).

A inserção da perspectiva humana - social, econômica, política e cultural - na abordagem ambiental parece ter se transformado num desafio para toda uma geração de estudiosos, intelectuais, cientistas e ambientalistas que estão engajados com tais discussões no presente, e com certeza no futuro próximo. Temse assim, diante deste importante desafio, uma forte tendência ao uso do termo socioambiental de forma ampla, de maneira que se tornou difícil e insuficiente falar de meio ambiente somente a partir da perspectiva da natureza, ao se pensar na problemática interação sociedade-natureza do presente, principalmente no que se refere 
BÊZ, M. \& FIGUEIREDO, L.C. Algumas reflexões acerca da Geografia ...

aos países em estágio de desenvolvimento complexo. O termo "sócio" aparece, então, conectado ao termo "ambiental" como forma de destacar o necessário envolvimento da sociedade enquanto sujeito, elemento, nó fundamental da rede de processos referentes à problemática ambiental contemporânea (MENDONÇA, 2001, p. 117).

Também se deve compreender que os pressupostos que permeiam a Geografia Socioambiental dialogam intrínseca e diretamente com a lógica do pensamento complexo. Para se ter uma definição do que vem a ser a complexidade, segundo Morin (1998), a percepção usual a concebe como inimiga da ordem e da clareza. Já uma percepção na lógica do pensamento complexo remete à desordem, como algo ligado à ordem, que por sua vez, é relativa ao sistema e à sua dinâmica no espaço-tempo.

Dessa forma, as atuais e as novas gerações devem ser mobilizadas e levadas a perceber o mundo e os problemas causados pelas gerações passadas e presentes, sob uma lógica linear e fragmentada, passando a percebê-lo numa outra lógica, a de saberpensar o espaço em sua complexidade. Tal perspectiva demanda um compromisso do pesquisador em trabalhar a comunidade partindo de uma visão complexa e dialética do mundo: perspectiva complexa por levar em consideração não somente as relações causais e de tensão no processo, mas também as interconectividades; perspectiva dialética, por conter no interior do movimento social, histórico, cultural, a tensão e a contradição como uma constante (NOGUEIRA, 2009).

O pensamento complexo nos remete aos princípios da incerteza, da imprevisibilidade, ao descontrole organizacional de um sistema, como é o caso do sistema capitalista; mas também nos remete aos princípios das relações, interrelações, das conexões, interconectividades das ligações. Camargo (2005) explicita melhor esta ideia ao afirmar que os sistemas complexos precisam ser pensados de acordo com as teorias da auto-organização, devido ao fato de suas variáveis serem expostas constantemente à imprevisibilidade, também devido à sua complexidade, ou seja, ao 
BÊZ, M. \& FIGUEIREDO, L.C. Algumas reflexões acerca da Geografia ...

grande número de variáveis que atuam conjuntamente no espaço, levando a caminhos não lineares, que se caracterizam pela previsibilidade zero.

$\mathrm{Na}$ perspectiva da Geografia Socioambiental, Leff traz a complexidade ambiental como uma nova racionalidade e um novo pensamento a respeito da produção do mundo embasado no conhecimento, na ciência e na tecnologia; como o espaço onde se articulam a natureza, a técnica e a cultura. A complexidade ambiental é definida como um processo de reconstrução de identidades resultantes da hibridação entre o material e o simbólico; um campo formado por atores sociais que se mobilizam para fazer uso da natureza; uma nova cultura que possibilita a construção de novas visões e o surgimento de novas estratégias de produção sustentável e democracia participativa (LEFF, 2003, p. 78).

Abordar a identidade de uma comunidade na lógica da complexidade implica pensá-la fora da lógica formal, trazendo-a para um mundo constituído por uma diversidade de identidades, compondo formas diferenciadas do ser e entranhando sentidos coletivos do povo. Na complexidade ambiental, a configuração das identidades e do ser surge como o posicionamento do indivíduo e de um povo no mundo; na formação de um ser que conduz estratégias de apropriação da natureza e a construção de mundos de vida variados (LEFF, 2003, p. 47).

Para trabalhar a comunidade em sua subjetividade, relações e processos deve-se partir do lugar, necessitando que se conheça a história e a espacialidade da mesma, procurando entender o que ali acontece. Callai (2005) relata a importância e a significância de se trabalhar o lugar em sua totalidade, como o espaço de vivência das pessoas-sujeitos de suas transformações. Ao abordar a não neutralidade do lugar, pensando-o como construção repleta de história e concretamente delimitada em um espaço e em um tempo, a autora afirma que o lugar não pode ser compreendido isoladamente. Como espaço onde escrevemos a história de nossas vidas, o lugar é o palco onde se sucedem os fenômenos, ele é 
BÊZ, M. \& FIGUEIREDO, L.C. Algumas reflexões acerca da Geografia ...

também ator/autor, uma vez que oferece condições, põe limites, cria possibilidades.

Dessa forma, não há como conceber o mundo de forma linear, estudando cada uma de suas partes separadamente (casa, rua, bairro, cidade, estado, país, continente), para depois juntá-las. No atual período histórico o mundo é fragmentado pelo processo de globalização que produz espaços da globalização, de forma que não existem espaços iguais, pelo contrário, há os espaços homogeneizados e homogeneizantes, os hierarquizados e os hierarquizantes, os que dão ordens e os que as cumprem. Mas o mundo não pode ser compreendido apenas como a soma de suas partes, ele é a totalidade, espaços que só fazem sentido no conjunto da totalidade (STRAFORINI, 2001, p. 50-51).

Para pensar e agir diante desta problemática é preciso mobilizar todos os segmentos da sociedade, propondo alternativas viáveis de serem implementadas. O conceito de mobilização é mais bem explicitado por Charlot (2000, p. 54-55) ao afirmar que "mobilizar é pôr em movimento; mobilizar-se é pôr-se em movimento.", ainda nesta linha de raciocínio, "Mobilizar é pôr recursos em movimento. Mobilizar-se é reunir suas forças, para fazer uso de si próprio como recurso".

Assim, para transformar mobilização em ação considera-se a relação dos sujeitos/moradores da comunidade com o saber, que é uma relação com o mundo, com eles mesmos e com os outros. É relação com o mundo visto como conjunto de significados, também como espaço de atividades, e se inscreve no tempo (Charlot, 2000, p. 78). Dessa maneira, o mundo é dado ao homem através do que ele percebe, imagina, pensa desse mundo, do que ele deseja, sente. $\mathrm{O}$ mundo se oferece a ele como conjunto de significados, do simbólico, onde se estabelecem as relações entre os sujeitos e os outros, entre o sujeito e ele mesmo. Nesse sentido, a relação com o saber é uma forma de relação com o mundo, notadamente com a linguagem (CHARLOT, 2000, p. 78).

Diante destas explanações que procuraram conceber $o$ natural e o social como elementos de um único processo, onde o 
BÊZ, M. \& FIGUEIREDO, L.C. Algumas reflexões acerca da Geografia ...

conhecimento na Geografia deixa de ser físico ou humano para se tornar geográfico, é necessário compreender os problemas socioambientais na lógica da complexidade. Estes problemas são sistemas complexos, nos quais interferem processos de diferentes racionalidades, ordens de materialidade e escalas espaçotemporais.

$\mathrm{O}$ tratamento das questões socioambientais, levando-se em consideração que representa visões e interesses distintos, não deve ser feito exclusivamente pelas ciências; é preciso que a população afetada participe integralmente das ações e decisões através do diálogo de saberes, relatando conhecimentos e fatos imprescindíveis para a transformação da realidade. Dessa maneira, os conflitos ambientais, que implicam visões e interesses diferenciados e nos quais se inscrevem diferentes formas de saber e estratégias de poder no saber, não poderão anular-se, segurar-se e reintegrar-se dentro do campo próprio das ciências; sua compreensão demanda uma abertura do cerco das ciências para um diálogo de saberes (LEFF, 2000, p. 37).

$\mathrm{O}$ entrelaçamento da ciência, pensada em sua interdisciplinaridade, e dos conhecimentos cotidianos constitui o elo de afirmação de que as transformações da natureza poderão ocorrer a partir do momento em que forem derrubadas as muralhas da diferença. Os processos que implicam um diálogo de saberes e as hibridizações entre ciência, tecnologia e saberes só poderão ser compreendidos e desembaraçados a partir da interdisciplinaridade. Não a interdisciplinaridade como prática teórico-metodológica, mas como um conjunto de práticas sociais que intervêm na construção do ambiente como um real complexo. Uma interdisciplinaridade ambiental definida como o campo de relações entre natureza e sociedade, entre ciências naturais e ciências sociais (LEFF, 2000).

Tais relações inter e transdisciplinares, para que ocorram fundamentadas no sujeito, devem proporcionar um "pensar sobre o mundo" a partir de um "pensar sobre si próprio", conhecer o mundo a partir de um conhecimento sobre si mesmo. Dessa 
BÊZ, M. \& FIGUEIREDO, L.C. Algumas reflexões acerca da Geografia ...

maneira, os processos pautados em uma lógica socioambiental, devem contribuir para que o homem possa conhecer a si próprio, na relação com o mundo e com o outro (NOGUEIRA, 2009).

Também é necessário deixar bem claro que a Geografia é uma das inúmeras ciências que abordam a temática socioambiental e que, na medida do possível, tem procurado equacionar as questões atinentes ao assunto. Mas é preciso que se sublinhe também, buscando uma salutar compreensão e interferência da problemática, que os grupos de pessoas que atuam devam ser compostos de especialistas das mais diversas áreas do conhecimento, completados por representantes da sociedade organizada e dirigentes políticos (MENDONÇA, 2005).

Nesse sentido, retomando as idéias de Mendonça (2005, p. 72), deve-se considerar que o tratamento do meio ambiente, mesmo assumindo um ponto de vista de alguma especificidade do conhecimento, não pode perder a visão do todo. Em outras palavras, numa relação dialética, esta discussão socioambiental é uma manifestação do geral, e precisa ser compreendida neste raciocínio de interligações particular-geral-particular.

Por isso, julga-se necessário ad-mirar as peculiaridades do pensamento socioambiental, no sentido de visualizar desde dentro, no movimento de ir e vir do todo às partes. Sendo importante no processo de abstração do espírito humano em compreender o concreto. O termo ad-mirar é fundamentado por Freire ao afirmar que este significa mirar de dentro, cindir para voltar a mirar o todo ad-mirado, sendo um movimento de ir até o todo e voltar até suas partes, são operações necessárias para o espírito abstrair para chegar ao objeto. São operações que se implicam mutuamente (FREIRE, 1981, p. 31).

Buscando teorizar sobre de que forma a realidade é dada ao homem, Freire $(1979$, p. 15) postula que a realidade é relegada aos homens, num primeiro momento, como objeto cognoscível por sua consciência crítica. Em outras palavras, na aproximação espontânea que o homem faz do mundo, a posição normal fundamental não é uma posição crítica, mas sim uma posição 
BÊZ, M. \& FIGUEIREDO, L.C. Algumas reflexões acerca da Geografia ... ingênua. Neste nível de espontaneidade, ao aproximar-se da realidade o homem faz simplesmente a experiência da realidade na qual ele está e procura.

Tal processo de tomada de consciência ainda não se constitui enquanto conscientização, devido ao fato desta consistir no desenvolvimento crítico da tomada de consciência. A conscientização implica em que se ultrapasse a esfera espontânea de apreensão da realidade, buscando chegar a uma esfera crítica que concebe a realidade como objeto cognoscível na qual o homem assume uma posição epistemológica. Ainda,

A conscientização é, neste sentido, um teste de realidade. Quanto mais conscientização, mais se "desvela" a realidade, mais se penetra na essência fenomênica do objeto, frente ao qual nos encontramos para analisá-lo. Por esta mesma razão, a conscientização não consiste em "estar frente à realidade" assumindo uma posição falsamente intelectual. A conscientização não pode existir fora da "práxis", ou melhor, sem o ato ação - reflexão. Esta unidade dialética constitui, de maneira permanente, o modo de ser ou de transformar o mundo que caracteriza os homens (FREIRE, 1979, p. 15).

A apropriação destes conceitos implica em um compromisso histórico, no qual os homens assumem o papel de sujeitos que fazem e refazem o mundo, exigindo que criem sua existência com um material que a vida lhes oferece. Tal conscientização baseia-se na relação consciência-mundo, proporcionando aos homens 0 esclarecimento da sua condição obscura resultante de sua aproximação com o mundo.

O que se tem a fazer, na verdade, é propor ao povo, por meio de certas contradições básicas, sua situação existencial, concreta, presente, como problema que o desafia e que, por sua vez, lhe exige resposta, não apenas no nível das idéias, mas no nível da ação. Não só dissertar sobre a prática e propor projetos que pouco ou nada tenham a ver com seus anseios, com suas dúvidas, com suas esperanças, com seus temores. É preciso falar ao povo sobre a 
BÊZ, M. \& FIGUEIREDO, L.C. Algumas reflexões acerca da Geografia ...

visão de mundo do cientista e fazê-la dialogar com a sua visão, uma visão que se manifesta nas várias formas de sua ação, reflete a sua situação no mundo, em que se constitui (FREIRE, 1987, p. 49).

\section{Comunidade e suas interrelações}

A visão de mundo das pessoas que habitam e compõem um espaço comum é importante como perspectiva de compreensão desta realidade, pois a estruturam e a vivenciam. Fazê-la dialogar com a visão do cientista, de forma a construir um pensamento coletivo que venha a contribuir para a proposição de ações locais, constitui uma alternativa de materialização do poder de transformação da voz do povo.

Viver em um lugar comum, compartilhando conflitos, a própria batalha diária pela sobrevivência, criando e recriando saberes, valores, significados, relações com este espaço podem vir a constituir o que se entende por comunidade. Para começar, de acordo com Bauman (2003), comunidade é entendida como um lugar "cálido", um lugar confortável e aconchegante onde todos se entendem bem, podem confiar no que ouvem, estão seguros a maior parte do tempo e raramente ficam desconcertados ou são surpreendidos.

$\mathrm{Na}$ comunidade idealizada pode-se contar com a boa vontade dos outros, se alguém tropeça e cai, os outros ajudarão a ficar em pé outra vez, ninguém vai rir de ninguém, nem ridicularizar por causa da falta de jeito; nesta existe a fraternidade, o perdão, a doação, a comunhão com o próximo. Porém vale lembrar que se vivem tempos implacáveis, tempos de competição e de desprezo pelos mais fracos, quando em resposta a um pedido de ajuda ouvem-se advertências para que cada um fique por sua conta e risco, tempos em que tudo o que a palavra comunidade evoca é aquilo que se sente falta e se precisa para viver seguros e confiantes.

Não é apenas a "dura realidade" declaradamente "não comunitária", diferentemente da comunidade imaginária que 
BÊZ, M. \& FIGUEIREDO, L.C. Algumas reflexões acerca da Geografia ...

produz uma "sensação de aconchego", que cria um problema para esta imagem concebida desta organização social. O que também se constitui como um obstáculo para esta é a diferença existente entre a comunidade dos sonhos e a "comunidade realmente existente", sendo que esta se constitui enquanto uma coletividade que pretende ser a comunidade encarnada, o sonho realizado, mas ao mesmo tempo exige lealdade incondicional e não permite traições.

Diante do atual contexto das questões socioambientais, em distintos espaços e suas relações, os serviços e os benefícios prestados pela comunidade, em alguns momentos, exigem que seus membros abram mão de algumas conquistas. A segurança oferecida por esta organização social exige que o indivíduo abra mão de sua liberdade; a confiança no próximo exige que não se confie em ninguém fora da comunidade; o entendimento mútuo requer a privação de falar com estranhos ou mesmo falar línguas estrangeiras; a proteção estabelece que ninguém acolha estranhos ou aja de modo esquisito; a dádiva do aconchego determina que sejam instalados alarmes em cada porta, câmeras de tevê no acesso, que ninguém chegue perto da janela e jamais abra a porta (BAUMAN, 2003).

Há um preço a pagar pelo privilégio de viver em comunidade, e este preço é pago em forma de liberdade. A segurança e a liberdade são dois valores igualmente preciosos e desejados, mas a atual forma de se conceber as "comunidades realmente existentes" torna a contradição entre estes dois valores mais visível e mais difícil de consertar. Dessa forma

A tensão entre a segurança e a liberdade e, portanto, ente a comunidade e a individualidade, provavelmente nunca será resolvida e assim continuará por muito tempo; não achar a solução correta e ficar frustrado com a solução adotada não nos levará a abandonar a busca - mas a continuar tentando. Sendo humanos, não podemos realizar a esperança, nem deixar de tê-la (BAUMAN, 2003, p. 11). 
BÊZ, M. \& FIGUEIREDO, L.C. Algumas reflexões acerca da Geografia ...

Pensar uma comunidade é refletir sobre as interrelações que se estabelecem com o espaço no qual se localiza, e estas conexões refletem o estágio de degradação ou de conservação da questão socioambiental desse contexto. Não apenas os problemas de caráter físico ou social, mas que surgem da complexa interação do homem com a natureza. Neste sentido, Leff (2007, p. 111) traz o homem como sujeito de suas próprias ações, destacando que "a questão ambiental é uma problemática de caráter eminentemente social: esta foi gerada e está atravessada por um conjunto de processos sociais".

Este movimento de ir e vir nos diálogos e reflexões acerca dos pressupostos socioambientais do pensamento geográfico, conectado ao conceito de comunidade como forma de promover iniciativas partindo do local, traduz a intrincada teia de nós que compõem a "Geografia da Vida". Não apenas iniciativas individuais que primem pelo conhecimento fragmentado, mas sim ações coletivas buscando ouvir e valorizar o outro (a outridade citada por Leff), levando em consideração que entre "eu e o mundo existe o outro", que possui uma história de vida, valores, saberes, sentimentos, em suma, uma intencionalidade.

Diante de um mundo rapidamente privatizado e individualizado, Bauman (2003) traz a identidade como substituta da comunidade, devido ao fato de que a instantaneidade das transformações possibilita que cada uma delas possa ser livremente imaginada, sem temer o teste da prática, como abrigo de segurança e confiança desejada com ardor. Para isso, com o objetivo de oferecer um mínimo de segurança e assim desempenhar uma espécie de papel tranquilizante e consolador, a identidade deve utilizar-se e ao mesmo tempo negar o papel de substituto da comunidade.

A afirmação de identidades no mundo que rapidamente se globaliza contrasta com o fortalecimento e o surgimento de novas fronteiras, que parecem ser erguidas em cada nova esquina de cada bairro decadente. Fronteiras estas que não foram traçadas para defender a singularidade das identidades já existentes, mas que 
BÊZ, M. \& FIGUEIREDO, L.C. Algumas reflexões acerca da Geografia ...

transformam as identidades comunitárias em subprodutos ou consequências do infindável processo de seu estabelecimento (BAUMAN, 2003).

A delimitação destas fronteiras visa oferecer a esperança de alívio e tranquilidade, que torna a comunidade dos sonhos tão atraente, aos indivíduos que acreditam que o lar comum foi encontrado. "A comunidade realmente existente" será diferente daquela de seus sonhos, sendo o seu contrário tanto mais semelhante: aumentará seus temores e inseguranças em vez de diluí-los ou deixá-los de lado. E é no combate diário para manter os estranhos fora dos muros e para caçar os traidores em seu próprio meio que o sentimento de estar em uma comunidade, de ser uma comunidade pode ser mantido e impedido de desaparecer. "O aconchego do lar deve ser buscado, cotidianamente, na linha de frente". (BAUMAN, 2003, p. 22).

Muitas são as transformações, as mudanças, as interconexões, os conflitos, as incertezas, as desordens, as trocas de sentimentos entre pessoas que compartilham um determinado espaço, e também de certa forma compartilham a própria vida com o outro; mas há uma emoção básica que deve estar presente para que seja possível a convivência harmônica (às vezes não tão harmônica assim) e a perpetuação do viver em comunidade: o amor. Esta emoção tão nobre busca abrir um espaço de interações recorrentes com o outro, no qual sua presença é legítima, sem exigências. Tal emoção tão complexa e conexa, por isso socioambiental, é definida por Maturana (1996) como, em termos biológicos, a disposição corporal para a ação sob a qual um realiza ações que constituem o outro como um legítimo outro em coexistência com um. O amor é a emoção fundante do social, sendo que quando um destrói o amor, desaparece a convivência social.

O amor está presente neste sentido coletivo de pertencimento a uma comunidade, de vivenciar as rupturas, de dialogar com os erros e os acertos, de construir conjuntamente, de respeitar e valorizar o outro. Mesmo quando existem muros 
BÊZ, M. \& FIGUEIREDO, L.C. Algumas reflexões acerca da Geografia ...

materiais ou subjetivos, forjados pela atual sociedade globalizada, a ligação entre as pessoas que vivem em uma comunidade e o significado de estar nesta organização social transpõe tal barreira e ressignifica sua própria existência.

Numa relação dialética de amor e rejeição, as transformações operadas pelos seres em seu ambiente acabam por transformar eles mesmos. O significado do viver e estar em uma comunidade também possui um lado negativo, no sentido de que a complexa interação homem e natureza, subjugando esta última às "necessidades" humanas, acaba por gerar produtos e subprodutos que não podem ser decompostos ou assimilados pelo meio. Morin, em sua obra $\mathrm{O}$ Método 1, deixa isto bem claro ao estruturar que "Todo ser age e retroage em seu ambiente. Toda atividade produtora tem efeitos múltiplos, diversos, complexos sobre o ambiente" (2005, p. 253). Nesta linha de raciocínio o mesmo autor conclui que:

Assim, os seres vivos transformam seu ambiente; autoproduzindo-se, eles se alimentam e co-produzem seu ecossistema, sempre o degradando por suas poluições, seus dejetos, suas predações (animais) e suas depredações (humanas) (2005, p. 253-254).

As organizações sociais e o ambiente são, sempre se mantendo diferentes um do outro, um no outro, cada um à sua maneira; da mesma forma, suas inseparáveis interações e relações mútuas são complementares, concorrentes e antagônicas. Enquanto o ambiente ao mesmo tempo alimenta e ameaça, faz existir e destrói, a organização transforma, polui e enriquece. De maneira retroativa, ser vivo e ambiente se unem de forma que um produz o outro reciprocamente, ou seja, as complexas interações moradores e comunidade acabam provocando rupturas e transformações recíprocas.

Estas rupturas e transformações provocadas pela valorização dos bens materiais (tendo a natureza como uma fonte ilimitada de matéria-prima), em nível local e global, acabam por ocasionar 
BÊZ, M. \& FIGUEIREDO, L.C. Algumas reflexões acerca da Geografia ...

problemas socioambientais em diferentes realidades. A crise ambiental, de acordo com Milton Santos (2006), reflete uma despreocupação com as especificidades do local e das realidades ambientais. A crise ambiental se produz neste mesmo período histórico, onde o poder das forças desencadeadas num lugar ultrapassa a capacidade local de controlá-las, nas condições atuais de mundialidade e de suas repercussões nacionais.

Frente à indiferença para com o local nos dias de hoje, a comunidade é procurada como abrigo contra as sucessivas correntezas de turbulência global, sendo que estas correntezas são originadas em lugares distantes que nenhuma localidade pode controlar por si só. Nesse viés, a construção de comunidades cercadas acaba por desviar o foco das fontes da insegurança, sendo que estas estão profundamente imbricadas na crescente distância entre a condição de "individualidade de jure" (real) e a tarefa de obter a "individualidade de facto" (imaginada) (BAUMAN, 2003).

Comunidade como um espaço onde se busca a segurança, que nega e interage com a liberdade; onde ocorre a valorização e o reconhecimento do outro como legítimo outro, onde as complexas e retroativas relações homem e natureza acontecem, por vezes gerando ações, reações, produtos e subprodutos; como uma reafirmação da identidade, na qual se vive e se está na comunidade; em suma, uma vida em comunhão com o outro. Porém, o sentido de comunidade já não é mais o mesmo, tanto no que se refere aos problemas socioambientais advindos das interrelações entre pessoas e comunidade, quanto aos valores que já não são mais construídos nesta organização social, como a segurança, o aconchego, a identidade individual e coletiva, a solidariedade, o respeito, a comunhão, dentre outros.

\section{Considerações finais}

Pensar a comunidade é pensar na própria Geografia Socioambiental, pois os pressupostos desta abordagem devem partir do local, bem como a multidimensionalidade inerente a este 
BÊZ, M. \& FIGUEIREDO, L.C. Algumas reflexões acerca da Geografia ...

espaço necessita de uma visão diferenciada do mundo e da vida. Refletir sobre as questões socioambientais dos lugares não quer dizer que serão considerados apenas os problemas, mas também as qualidades, os valores, os conhecimentos, as emoções, as intencionalidades, as percepções, e tudo aquilo que os moradores da comunidade construírem e ressignificarem ao longo das vivências neste contexto.

A natureza cambiante do mundo contemporâneo exige a simultaneidade de novos olhares, novas técnicas e novas perspectivas sobre o objeto de estudo da Geografia. Impõe também a abertura das mentes para se criar o novo, o diferente, superando o atual estágio de dificuldades e limitações de apreensão do real que ainda fortemente caracteriza o presente. Um novo pensamento, capaz de provocar mudanças, não se concretiza se não houver um diálogo de saberes distintos e sem considerar as resistências. Neste contexto é preciso estar aberto, ser criativo e ousado o suficiente para propor alterações e criar possibilidades para o surgimento de novas propostas como a Geografia Socioambiental.

Sendo assim, neste mundo onde todos os seres são interdependentes, há tarefas que podem ser enfrentadas por cada indivíduo, mas com as quais não se pode lidar individualmente. As barreiras que levam a manter a distância dos outros, a estabelecer limites e barricadas, tornam a administração dessas tarefas ainda mais difícil. Todos precisam ter controle sobre as condições com as quais se enfrentam os desafios da vida, porém para a maioria esse controle só pode ser obtido coletivamente.

É justamente neste momento que a comunidade mais faz falta, sendo que também aqui reside a chance de que a comunidade venha a se realizar. Se vier a existir uma comunidade no mundo dos indivíduos, só poderá ser (e precisa sê-lo) tecida em conjunto a partir do compartilhamento e do cuidado mútuo; uma comunidade de responsabilidade e de interesse no que se refere aos direitos iguais de todos serem humanos e de igual capacidade de agir em defesa desses direitos. 
BÊZ, M. \& FIGUEIREDO, L.C. Algumas reflexões acerca da Geografia ...

\section{Referências bibliográficas}

BAUMAN, Zygmunt. Comunidade: a busca por segurança no mundo atual. Trad: Plínio Dentzien. Rio de Janeiro: Jorge Zahar, 2003.

CALLAI, Helena Copetti. Aprendendo a ler o mundo: a Geografia nos anos iniciais do ensino fundamental. Cadernos CEDES, Campinas, p. 227-247, maio/ago. 2005. Disponível em: $<\mathrm{http}: / /$ www.scielo.br/pdf/ccedes/v25n66/a06v2566.pdf $>$. Acesso em: 10 jul. 2010.

CAMARGO, Luís Henrique Ramos de. A ruptura do meio ambiente. Conhecendo as mudanças ambientais do planeta através de uma nova percepção da ciência: a Geografia da complexidade. Rio de Janeiro: Bertrand Brasil, 2005.

CHARLOT, Bernard. Da relação com o saber: elementos para uma teoria. Trad. Bruno Magne. Porto Alegre: Artes Médicas Sul, 2000.

FREIRE, Paulo. Ação cultural para a liberdade. 5. ed. Rio de Janeiro: Paz e Terra, 1981. 120 p.

Conscientização: teoria e prática da libertação: uma introdução ao pensamento de Paulo Freire. Trad: Kátia de Mello e Silva. São Paulo: Cortez \& Moraes, 1979. 53 p.

Paz e Terra, 1987. 107 p.

. Pedagogia do oprimido. 17. ed. Rio de janeiro:

LEFF, Enrique. Complexidade, Interdisciplinaridade e Saber Ambiental. In: JUNIOR, Arlindo Philippi et al. Interdisciplinaridade em Ciências Ambientais. São Paulo: Signus Editora, 2000, p. 19-51. 
BÊZ, M. \& FIGUEIREDO, L.C. Algumas reflexões acerca da Geografia ...

. Pensar a complexidade ambiental. In: LEFF, E.

(Coord.). A complexidade ambiental. Trad. Eliete Wolff. São Paulo: Cortez, 2003.

Epistemologia ambiental. Trad: Sandra Valenzuela. 4. ed. São Paulo: Cortez, 2007.

MATURANA, Humberto. EI sentido de lo humano. 8. ed. Santa Elena: Productora Gráfica Andros Ltda., 1996.

MENDONÇA, Francisco de Assis. Geografia Socioambiental. In: Terra Livre, n. 16, p. 113-132, $1^{\circ}$ sem. 2001.

. Geografia e meio ambiente. 8 . ed. São Paulo: Contexto, 2005. 80 p. (Caminhos da Geografia).

MORIN, Edgar. Ciência com consciência. Rio de Janeiro: Bertrand Brasil, 1998.

O método 1: a natureza da natureza. Trad: Ilana Heineberg. 2. ed. Porto Alegre: Sulina, 2005.

NOGUEIRA, Valdir. Educação Geográfica e Formação da Consciência Espacial-Cidadã no Ensino Fundamental: Sujeitos, Saberes e Práticas. 2009. 369f. Tese (Doutorado em Educação) Universidade Federal do Paraná, Curitiba, 2009.

. Os saberes na Educação Geográfica: tecendo uma rede de conceitos e temas voltados à compreensão da espacialidade geográfica. In: NOGUEIRA, V. Bases referenciais da Educação Geográfica na formação da consciência espacialcidadã. Curitiba: Editora da Universidade Federal do Paraná, 2010. 
BÊZ, M. \& FIGUEIREDO, L.C. Algumas reflexões acerca da Geografia ... SANTOS, Milton. A natureza do espaço: técnica e tempo, razão e emoção. 4. ed. São Paulo: Ed. da Universidade de São Paulo, 2006.

STRAFORINI, Rafael. Ensinar geografia nas séries iniciais: o desafio da totalidade mundo. 2001. 155f. Dissertação (Mestrado em Educação Aplicada às Geociências) - Universidade Estadual de Campinas, Campinas, 2001.

Recebido em outubro de 2011

Aceito em junho de 2012 